\title{
Examining Digital Advertising using an Affect Transfer Hypothesis
}

\section{Structured Abstract}

\section{Purpose}

This paper aims to develop a framework for understanding consumers' response to digital advertising using the Affect Transfer Hypotheses and incorporating search behaviors. The paper also offers future research needs in this area.

\section{Design/methodology/approach}

A quantitative approach is employed in this paper using survey research and a research panel based sample. Structural equation modeling with multi-group comparisons is conducted. The research is conducted using a general US population sample.

\section{Findings}

The Affect Transfer Hypothesis is a sufficient model for explaining consumers' response to digital advertising, but it is made more exhaustive with the incorporation of search intentions. The authors identify key research gaps and offer recommended future research opportunities.

\section{Originality/value}

To date, little research in digital marketing has studied search intentions and less has done so in the context of digital video advertising. Interestingly, theory from more a traditional marketing domain can further our understanding in a digital one.

\section{Keywords}




\section{Examining Digital Advertising using an Affect Transfer Hypothesis}

Consumers have ubiquitous access to endless amounts of information, and with marketers focused on providing seamless customer experiences across all available marketing platforms; consumers are almost able to make a purchase at anytime. The days of watching a TV ad and having a lag until purchase are behind us. Moreover, the way people purchase products and services is evolving due to online capabilities. For many, the purchase journey begins information from advertising or search. Digital advertising and Search Engine Marketing expenditures are predicted to grow and even surpass TV advertising expenditures (eMarketer 2016). Internet use continues to increase due to increases in the number of consumers globally who are online and the proportion of those users who access the Internet on mobile devices. It is predicted that in 2017 there will be over 2 billion smartphone users across the globe (eMarketer 2014a), one-tenth of whom will live in the United States. Understanding how consumers use advertising and search in their purchase process is essential to optimizing future shifts in speeding.

In addition, with major corporations like Google and Facebook working to establish Internet and cellular networks in the most remote parts of the world, it is predicted that within 20 years the whole world will have Internet and cellular service access. As of 2015, there are 3.17 billion internet users worldwide, up from 1.02 billion in 2005 and 2.02 billion in 2010 (Statista 2015). Consequently, digital advertising expenditures are increasing. In particular, video is regarded as the most dynamic form of digital advertising. Whether embedded in websites or apps, video advertisements are the prevailing digital marketing format, and consequently the context of this research. According to estimates made by the Interactive Advertising Bureau (IAB), the revenue from US digital video advertising is predicted to top $\$ 5$ billion in 2015 , and reach $\$ 13.3$ 
billion by 2020 (Hoelzel 2015). Thus, digital video advertising is the context within which the digital buying process is studied.

Marketing research must enhance our understanding of how digital advertising influences consumers' purchase in the digital environment. Few studies have examined how advertising influences consumers' intentions to search for product information, however, recent changes in marketing spending and consumer behavior suggest such an inquiry is warranted. Marketers require a clearer understanding of how digital advertising affects consumers' on digital platforms. This article contributes to advertising literature in two ways. First, we extend an established theory of advertising effectiveness to better explain digital consumer behavior by incorporating digital relevant metrics of information search and click-through behavior to the model. Second, we further extend the theory to explain how the degree of a consumer's personal involvement with the product being advertised affects the purchase process.

\section{THEORETICAL FRAMEWORK}

This research study aims to apply the Affect Transfer Hypothesis (Mitchell and Olson 2000) and Dual Mediation Hypothesis (Lutz, MacKenzie and Belch 1983) of advertising to examine the processes through which digital video advertising influences a digital consumer process. In their two seminal studies MacKenzie, Lutz, and Belch $(1986,1989)$ examine attitude towards advertisements as a mechanism through which ads are effective. Because search is believed to be on of many integral elements in digital marketing, we tease apart the relationship between the elements of these models (Figure 1) and integrate search related metrics into the model. 
Figure 1: Foundational Advertising Process Model

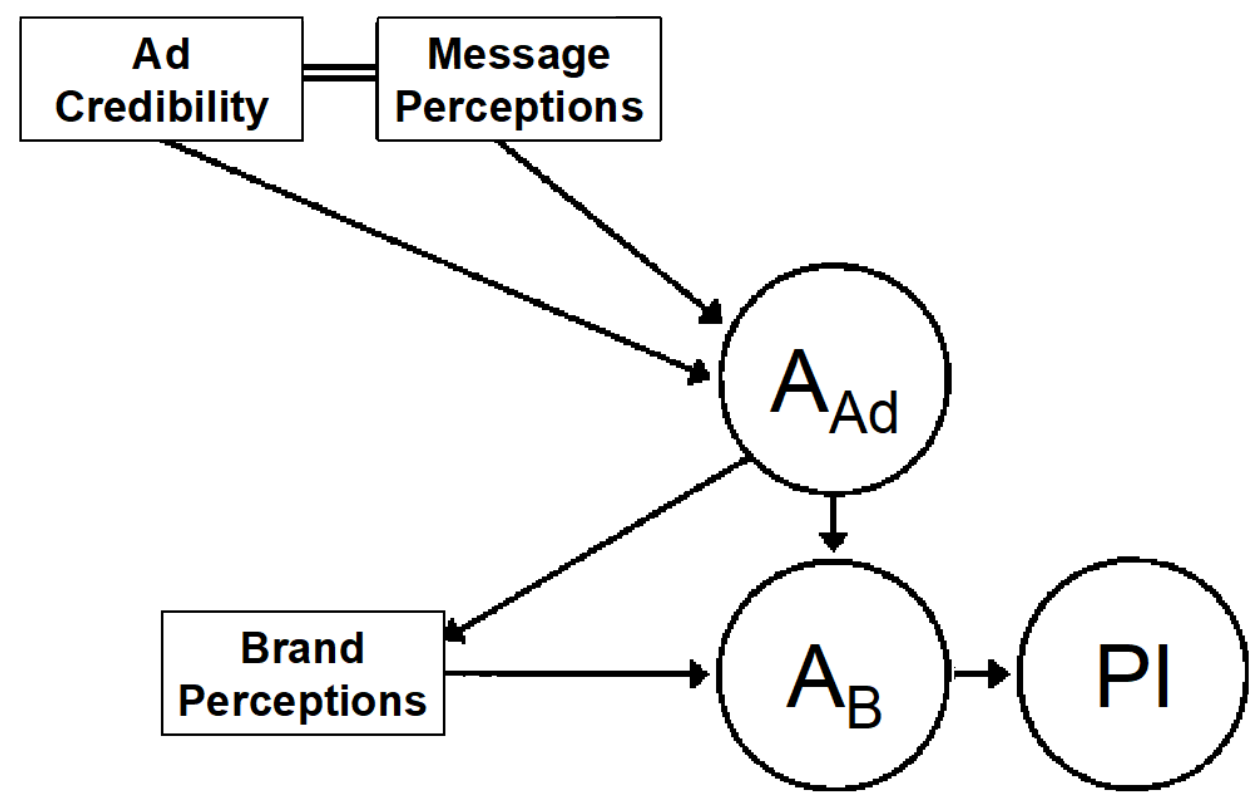

Notes: Measures in model included:

1. Ad Credibility - the perceived credibility of adverting, or how truthful or believable the audience perceives the assertions made about the brand to be.

2. Ad perceptions - Perceptions of the informativeness and quality of the ad execution

3. Brand perceptions - recipients' perceptions of the brand being advertised

Richard J. Lutz, Scott B. MacKenzie, and George E. Belch (1983), "Attitude Toward the Ad As a Mediator of Advertising Effectiveness: Determinants and Consequences", in NA - Advances in Consumer Research Volume 10, eds. Richard P. Bagozzi and Alice M. Tybout, Ann Abor, MI : Association for Consumer Research, Pages: 532-539.

The Affect Transfer Hypothesis of advertising elucidates the way in which perceptions of an advertisement might influence attitudes toward the advertisement $\left(\mathrm{A}_{\mathrm{Ad}}\right)$. The attitudes in turn influences attitudes towards a brand $\left(\mathrm{A}_{\mathrm{B}}\right)$ (Mitchell and Olson 2000). Two perceptions of note are message quality and ad credibility (Lutz, MacKenzie and Belch 1983; MacKenzie, Belch and Lutz 1986). Both are believed to influence $A_{A d}$ (Figure 1). Attitudes towards an advertisement ( $\left.\mathrm{A}_{\mathrm{Ad}}\right)$ are then shown to influence $A_{B}$, which ultimately influence purchase intentions (PI). This model is 
appropriate for explaining how advertising influences consumers in a digital context. Interestingly, one industry source supports that digital channels are now the method of choice for consumers' product research (eMarketer 2014c). However, the aforementioned model does not incorporate search related constructs. Thus, search intentions and likelihood of click-through are two factors of the digital advertising process that might be added to the Affect Transfer Hypothesis model to expand our understanding of digital advertising effectiveness. This extension is depicted in Figure 2. 
Figure 2: Proposed theoretical model of the digital advertising process

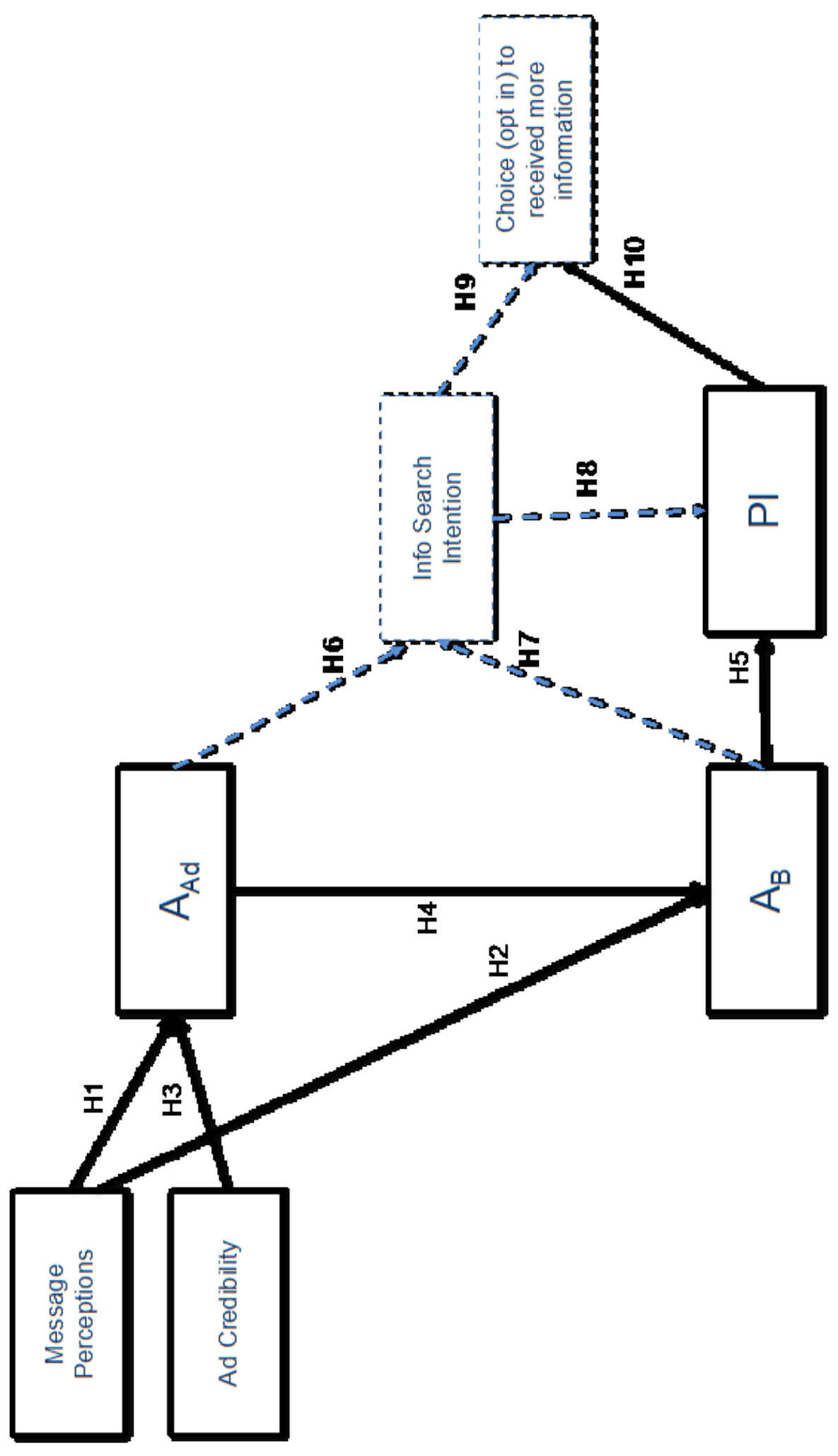




\section{A Digital Ad Process}

In an earlier work, Mitchell and Olson (2000) anchor advertising effectiveness to attitudes towards the message. Moreover, MacKenzie, Belch and Lutz (1986) test five major propositions and explain how traditional forms of advertising work to affect consumers' purchase. The original model is replicated in hypotheses 1-5.

Message Perceptions. The first proposition is that ad cognitions affect attitudes towards the massage. These ad cognitions reflect consumers' thoughts about the message and elements of the message. According to the ELM (Petty and Cacioppo 1986), message perceptions refer to an individual's subjective perception of the arguments in the message. That is, consumers perceive the same advertisement differently based on their subjective perceptions. In accordance with the ELM, early models of traditional advertising effectiveness support advertisements perceived as high quality are related to positive attitudes toward the message. Accordingly, consumers who perceive ads to be less believable, clear, and realistic should have less favorable attitudes towards that ad. Thus, we propose the following hypothesis:

H1: Message perceptions will be positively related to attitudes towards the advertisement, such that perceptions of high quality will be related to more favorable $A_{\text {Ad. }}$.

It is important to note that in MacKenzie et al (1986), brand perceptions, not message perceptions, influence brand attitudes. However, brand perceptions, according to Aaker (1991), are the category of attributes 'linked' in memory to a brand. Thus, in the case of fictitious or new brands, these perceptions of the ad/message are believed take reflect brand perceptions for novel or new brands, since existing memories of the brand do not yet exist. Thus:

H2: Message perceptions will be positively related with attitudes towards the brand, such that perceptions of higher quality will be related to more favorable $A_{B}$. 
Perceived Ad Credibility. A second proposition of earlier advertising models is that ad credibility affects ad attitudes. Credibility refers to the objective and subjective components of the believability of a source or message. Media and advertising credibility can be defined as the extent to which the consumer believes or trusts in the media or advertising claims (Moore and Rodgers 2005).

According to Petty and Cacioppo (1986), source expertise influences recipients' perceptions and attitudes towards a persuasive message. High credibility sources have been found to be more persuasive than low credibility sources (MacKenzie, Lutz and Belch 1986; Petty \& Wegener 1998; Pornpitakpan 2004; Sinkovics, Pezderka and Haghirian 2012; Yang, Kim and Yoo 20013). Thus, this research contends:

H3: Perceived ad credibility will be positively associated with $\mathrm{A}_{\mathrm{Ad}}$, such that positive perceptions of an ad's credibility will be related to more favorable $\mathrm{A}_{\mathrm{Ad}}$.

Relationships between Attitudes and Intentions. Many studies have demonstrated the effect of a consumer's attitude towards an advertisement on their attitude towards a brand and their purchase intention (Brown and Stayman 1992; Gardner 1985; MacKenzie and Lutz 1989; MacKenzie, Lutz, and Belch 1986; Shimp 1981). Attitude towards an advertisement refers to a subjective response to a particular advertisement at the time of exposure in a favorable or unfavorable manner (Lutz 1985). Shimp (1981) argues that attitude towards an ad is transferred to the brand, which in turn predicts consumers' intentions. MacKenzie and Lutz (1989) found positive direct relationship between attitudes towards an advertisement and attitude towards the brand. Accordingly, we hypothesize:

H4: $A_{A d}$ will be positively associated with $A_{B}$, such that favorable $A_{\text {Ad }}$ will be associated with favorable $A_{B}$. 
Successively, attitudes towards advertisements have been shown to indirectly influence consumers purchase intentions, through brand attitudes, which directly influence purchase intentions (Yazdanparast and Spears 2013; Merchant and Rose 2013; Spears and Singh 2004; Brown, Homer, and Inman 1998; Burke and Edell 1989; Edell and Burke 1987; MacKenzie and Lutz 1989; MacKenzie, Lutz, and Belch 1986; Batra and Ray 1986). Accordingly, this study hypothesizes:

H5: $A_{B}$ will be positively associated with PI, such that positive $A_{B}$ will be related to stronger PI.

\section{Theoretical Extension}

Interestingly, the relationship between attitudes and other consumer intentions may be important to examine due to the unique characteristics and utilization of digital platforms (Maity and Arnold 2013; Punj 2012; Vatanparast \& Asil 2007). Specifcally, digital platforms afford consumers immediate access to information to aid their advertising process and the lag between ad exposure and action are nearly eradicated. If consumers are interested in an advertised product they might search for more information about it. Consequently, consumers' intention to search for more information about a product a function of digital advertising may be an appropriate relationship to examine in a digital advertising process (Häubl and Trifts 2000). Additionally, prior models such as the Attitude Belief Model and the Theory of Reasoned Action substantiate the prediction of search intentions by attitudes (Fishbein 1979; Muk and Chung 2015). Thus, we extend the Affect Transfer Hypotheses of advertising effectiveness by testing the relationship between attitudes, product information search intentions and purchase intentions, and beg the questions: 
RQ1: Will $A_{A d}$ be positively associated with intention to search for product information, such that positive $A_{\text {Ad }}$ will be associated with stronger search intentions.

RQ2: Will $A_{B}$ be positively associated with intention to search for information, such that positive $A_{B}$ will be related to stronger search intentions.

Intentions to Information Search and Intentions to Purchase. According to Shim,

Eastlick, Lotz, and Warrington (2001), consumers' intention to search for product information is a key predictor of consumers' online purchasing intentions. Thus, it is reasonable to assume that following exposure to an advertisement, consumers' intentions to search for information about the advertised brand may influence subsequent intentions to purchase the product. According to theories regarding consumers' advertising process, consumers need to gather information to decide whether they might want to buy the product or not (Laroche, Kim, and Zhou 1996). Thus, this research posits:

H5: Intention to search for product information will be positively associated with PI, such that stronger intentions to search for product information will be associated with stronger PI.

Intention and Choice. Finally, this study attempts to explore the association between behavioral intentions and actual behavior to inform integrated marketing strategies. Researchers argue that volitional behaviors such as clicking through in an app or web-browser after receiving a prompt to click-through to receive product information can be predicted by prior intentions. These intentions are defined as "a measure of the likelihood that a person will engage in a given behavior" (Ajzen and Fishbein 1980, p. 41). Thus, it is reasonable to assert that people are more likely to click-through to receive more product information when they have stronger intentions towards the advertised product. 
H6: Intention to search for information will be positively associated with the likelihood of clicking-through to receive product information, such that a consumer will be more likely to click-through to receive more information when their intentions to search are stronger.

H7: PI will be positively associated with the likelihood of clicking-through to receive product information, such that a consumer will be more likely to click-through to receive more information when their PIs are stronger.

Hypotheses 1-7 and research questions 1 ands 2 are graphically represented in Figure 2.

\section{The Dual Nature of the Digital Buying Process}

To ensure a richer understanding of how digital advertising works, a robust parameter of information processing is tested. According to the Elaboration Likelihood Model (ELM), people process information through either a central or peripheral route (Petty and Cacioppo 1986). People who have high motivation and/or ability tend to engage in central route processing, while those who have low motivation and ability tend to engage in peripheral route processing.

Similarly, the Heuristic Systematic Model (HSM) posits two types of information processing: systematic processing that encompasses the central route, and heuristic processing which is similar to the peripheral route of persuasion (Chaiken and Maheswaran 1994). The major difference between the ELM and the HSM is that the HSM posits that two ways of information processing can co-occur with one predominating in some instances, whereas the ELM posits the independent role of the two routes of persuasion (Stiff 1986; Stiff and Boster 1987). The ELM and the HSM have been widely applied to research attempting to explicate how consumers process advertising messages regarding various marketing communication variables such as source (Goldsmith et al. 2000; Petty et al. 1983; Reinhard and Sporer 2015), and message (Andrews and 
Shimp 1990; Petty et al. 1983; Worthington, NussBaum, and Parrott 2015). Consequently, the HSM serves as the theoretical framework for this research, as the systematic and heuristic processes are believed to co-occur.

Consistent with the HSM, one major tenant of the proposed model of the digital advertising process is that consumers' involvement can affect which process will be activated (Matthes 2013; Chang, Hsieh and Tseng 2013). Here, involvement refers to the extent to which an individual perceives that a topic or issue in a message is personally relevant to them (Petty et al. 1983). When consumers are highly motivated in the purchase process they tend to engage in a more effortful deliberate process. Thus, the extended digital model of the Affect Transfer Hypothesis might be moderated by consumers' involvement.

In particular, research has shown that attitudes are more predictive of intentions when consumers are involved in a deliberate purchase process (Fazio and Zanna 1981; MacKenzie, Lutz and Belch 1986). On the other hand, when involvement is low, non-deliberate attitudes are weaker predictors of behavior (Olson and Fazio 2008; Sherman and Fazio 1983). In turn, when involvement is high, the predictive power of an attitude on subsequent behavior in stronger (Glasman and Albarracín 2006; Petty, Haugtvedt, and Smith 1995). We propose that this effect will persist for other types of intentions in the digital space such that:

H8a: Brand attitudes will be stronger predictors of search intentions when involvement is high, compared to when involvement is low.

H8b: Brand attitudes will be stronger predictors of purchase intentions when involvement is high, compared to when involvement is low.

Similarly, consumers are more likely to exert effort, act, or purchase a product when involvement is high (Ajzen and Fishbein 1977; Petty et al. 1983). Thus, in this study, the 
relationship between purchase intentions and click-through likelihood and the relationship between search intentions and click-through should be stronger when involvement is high, compared to when involvement is low. Thus, the authors argue:

H9a: Search intentions will be a stronger predictor of consumers' likelihood to clickthrough for more product information when involvement is high, compared to when involvement is low.

H9b: Purchase intentions will be a stronger predictor of consumers' likelihood to clickthrough for more product information when involvement is high, compared to when involvement is low.

\section{METHODS}

\section{Design and Procedure}

To examine the advertising process in a digital context, a survey was administered online. A research company, Critical Mix, recruited participants from an online panel. Members of the research panel received an invitation to participate in the online study by clicking on a URL. Upon clicking the study URL, consumers reported the type of digital platform they were on, and then participants responded to a series of manipulation checks that confirmed the platform they were using. Moreover, participants clarified their device by selecting "what their platform looks like" based on an image (Appendix A). Cross referencing these two checks revealed 96\% accuracy across all platforms. Furthermore, all indicated that they had the adequate software to view the digital advertisements they would respond too. Following the robustness checks, participants responded to a demographic profile. The accrued sample was relatively balanced across platform type, with $35 \%$ using a laptop, $38 \%$ using a tablet, and $28 \%$ using a smartphone. 
Within the survey, participants were presented eight digital video ads in random order. This was one of three strategies we used to minimize for common method variance (CMV). After viewing the first stimulus, participants reported their attitudes towards the ad, attitudes towards the brand featured in the ad, intentions to seek more information about the product, and purchase intentions for the product. These measures were presented in random order as a second strategy to account for CMV. Lastly, to measure a behavioral response, participants were given a choice to receive more information about the product advertised or not. This process was repeated for each of the seven remaining ads.

A third strategy to minimize CMV was to analyze the data of consumers' response to only the first ad shown. By modeling the consumers' responses to only the first ad, we were able to generalize the model to the digital advertising process across multiple product types. Random presentation of each ad (e.g., across product types) reduced confounding by equalizing concomitant factors that have not been accounted for in the experimental design (Jo 2008). The generalizability of the results was enhanced through our design, as the digital buying process for eight different ads were assessed across three platform types within one general model.

\section{Stimuli}

The stimuli were created for this research using foreign brands, largely unknown in the U.S (Appendix B). This was to control for brand familiarly. A consultant adapted TV ads into 15second commercials for twelve different consumer offerings. These offerings included hedonic and utilitarian, as well as high and low involvement options (i.e., toothpaste and detergent (low involvement utilitarian), chocolate and scented candles (low involvement hedonic), a minivan and a laptop (high involvement utilitarian), and a cruise and a music festival (high hedonic). The purpose of using eight different products was to enhance the authors' ability to generalize the 
results of varying products to a general digital advertising process. Focus groups with eight upperlevel undergraduate advertising majors were conducted at a southwestern university to pre-test that the ads. These participants served as judges and evaluated the advertisements realism and the products categorization. Evaluations of advertisements as good/bad, for similar offerings, did not significantly $(p<.05)$ differ from each other (Appendix C). Participants negatively rate realism of four ads, so they were not used in the study.

\section{Study Measures}

Message Perceptions. Participants' perception of the advertising messages quality $(\alpha=.93)$ was assessed using a 7-point semantic differential scale adapted from prior research (Beltramini, 1988; Slater \& Rouner, 1996). The scale consisted of three word pairs as follows: "I felt or thought the advertisement I just saw was... realistic/unrealistic, believable/unbelievable, and clear/unclear."

Perceived Ad Credibility. The extent to which participants perceived the message as credible $(\alpha=.90)$ was assessed using a 7-point Likert scale adapted from prior research (Dholakia and Sternthal 1977; Harmon and Coney 1982; Ohanian 1991). The scale consisted of five descriptors, with which participants of the study strong-agreed/strongly-disagreed that advertisements are... reliable, honest, clear, credible, truthful.

Involvement. Asking consumers "are you currently in the market to buy this product" assessed the extent to which the advertised product was personally relevant to the participant? Participants who said yes were assigned to the high involvement category $=1$, and those who said no were assigned to the low involvement category $=0$.

Responses to advertising included four multi-item scales measuring attitude towards the advertisement, attitude towards the brand, intention to search for information about the product, 
and purchase intention. A final advertising response was a binary scale measuring whether the respondent chose (clicked-through) to receive additional information about the product advertised. The dependent measures, as operationalized in the survey, are summarized in Table 1 below.

Attitude towards the ad and brand. Participants' attitudes towards the ad $(\alpha=.82)$ and brand $(\alpha=.80)$ were assessed with 7-point semantic differential scale adopted from prior research (MacKenzie et al. 1986). Four word pairs were used to assess participants' attitude towards the advertisement likeable/unlikeable, interesting/uninteresting, good/bad, and irritating/not irritating. Three word pairs were used to assess participants' attitude towards the brand likeable/unlikeable, pleasant/unpleasant, and good/bad.

Information search intention. The extent to which participants intended to seek additional information about the advertised products was measured with a 7-point Likert scale (1-strongly disagree, 7-strongly agree) adapted from prior research (Biswas, Pullig, Yagci, and Dean 2002; Dutta-Bergman 2003; Yang 2012). The scale consisted of three items $(\alpha=.94)$. An example item includes "I will spend time search information about the product advertised."

Purchase intention. The extent to which participants would like to buy the advertised product was assessed with a 7-point semantic differential scale adopted from prior research (MacKenzie et al. 1986). The following three word pairs were used to assess participants' intention to buy the advertised products: likely/unlikely, probable/improbable, and possible/impossible ( $\alpha$ $=.85)$.

Click-through for more information. Similar to click through behaviors in digital marketing, consumer's choice was measured by asking participants "Please choose whether you would like more information about the product in the advertisement you just viewed." They could select yes $=1$ and no $=0$. Thus, the actual choice, rather than their preference or intentions was observed. 


\section{Control Variables}

Age and gender were assessed as control variables. Additionally, the type of device the participant used during the study was assessed. This variable may affect consumers' credibility perceptions of advertising, such that perceptions of ads on mobile devices (vs. computers) are less positive (Stewart and Cunningham, in press). Moreover, device ownership and usage differs by device type, age (Anderson, 2015; eMarketer 2015c), Consequently, consumers were asked what device they were on, mobile or laptop. 
Table 1: Summary of variables measured

\begin{tabular}{|c|c|}
\hline Variables & Measures \\
\hline \multirow{3}{*}{$\begin{array}{l}\text { Message } \\
\text { perceptions }\end{array}$} & $\begin{array}{l}\text { I felt or thought the advertisement I just saw was... Realistic - Unrealistic (7- } \\
\text { point) }\end{array}$ \\
\hline & $\begin{array}{l}\text { Ifelt or thought the advertisement I just saw was...Believable - Unbelievable } \\
\text { (7-point) }\end{array}$ \\
\hline & I felt or thought the advertisement I just saw was...Clear-Unclear (7-point) \\
\hline \multirow{5}{*}{$\begin{array}{l}\text { Perceived } \\
\text { Ad perceptions }\end{array}$} & $\begin{array}{l}\text { As a source of information for purchase decisions, the platform I'm currently } \\
\text { using is... reliable (7-point) }\end{array}$ \\
\hline & $\begin{array}{l}\text { As a source of information for purchase decisions, the platform I'm currently } \\
\text { using is... honest (7-point) }\end{array}$ \\
\hline & $\begin{array}{l}\text { As a source of information for purchase decisions, the platform I'm currently } \\
\text { using is... clear (7-point) }\end{array}$ \\
\hline & $\begin{array}{l}\text { As a source of information for purchase decisions, the platform I'm currently } \\
\text { using is... truthful (7-point) }\end{array}$ \\
\hline & $\begin{array}{l}\text { As a source of information for purchase decisions, the platform I'm currently } \\
\text { using is... credible (7-point) }\end{array}$ \\
\hline $\begin{array}{l}\text { Personal } \\
\text { Involvement }\end{array}$ & Are you currently in the market to purchase this product? $0=$ No or $1=$ Yes \\
\hline \multirow{4}{*}{$\begin{array}{l}\text { Attitude towards } \\
\text { the Ad }\end{array}$} & $\begin{array}{l}\text { Please describe the advertisement you just saw as ... Likable - Unlikable (7- } \\
\text { point) }\end{array}$ \\
\hline & $\begin{array}{l}\text { Please describe the advertisement you just saw as ...Interesting - } \\
\text { Uninteresting (7-point) }\end{array}$ \\
\hline & Please describe the advertisement you just saw as ...Good - Bad (7-point) \\
\hline & $\begin{array}{l}\text { Please describe the advertisement you just saw as ...Irritating - Not irritating } \\
\text { (7-point) }\end{array}$ \\
\hline \multirow{3}{*}{$\begin{array}{l}\text { Attitude towards } \\
\text { the Brand }\end{array}$} & $\begin{array}{l}\text { Please evaluate the brand from the ad you just saw as ... Likeable - } \\
\text { Unlikeable (7-point) (7-point) }\end{array}$ \\
\hline & $\begin{array}{l}\text { Please evaluate the brand from the ad you just saw as ...Pleasant - } \\
\text { Unpleasant (7-point) }\end{array}$ \\
\hline & Please evaluate the brand from the ad you just saw as ...Good-Bad (7-point) \\
\hline \multirow{3}{*}{$\begin{array}{l}\text { Information } \\
\text { Search Intention }\end{array}$} & I will ...Spend time search information about the product advertised (7-point) \\
\hline & I intend to ... Speak to friends about the product advertised (7-point) \\
\hline & I intend to ...Search for information about the product advertised (7-point) \\
\hline \multirow{3}{*}{$\begin{array}{l}\text { Purchase } \\
\text { Intention }\end{array}$} & $\begin{array}{l}\text { My purchasing the product in the advertisement I just saw is...Likely- } \\
\text { Unlikely (7-point) }\end{array}$ \\
\hline & $\begin{array}{l}\text { My purchasing the product in the advertisement I just saw is...Probable- } \\
\text { Improbable (7-point) }\end{array}$ \\
\hline & $\begin{array}{l}\text { My purchasing the product in the advertisement I just saw is...Possible - } \\
\text { Impossible (7-point) }\end{array}$ \\
\hline $\begin{array}{l}\text { Choice to Receive } \\
\text { More Information }\end{array}$ & $\begin{array}{l}\text { Please choose whether you would like more information about the product in } \\
\text { the advertisement you just viewed. (Yes or No) }\end{array}$ \\
\hline
\end{tabular}




\section{Sample}

The total number of panel members that accessed the study was 7256 . The final sample included 1725 participants, which corresponds to a $23.8 \%$ response rate. The quality of quasiexperimental data resulting from research conducted online can be severely hampered (Albaum, Roster, and Smith 2015). Participants were flagged if they were located 3 deviations from the mean with respect to (1) the variability in their responses; (2) the speed with which they completed the survey, as both serve as a proxy for speeding through and not answering questions carefully; and (3) whether they incorrectly answered a quality screener question for which they had 2 chances to complete accurately, which assessed how carefully they read directions. Participants were removed from the sample if they were flagged for two or three of the three checks. This resulted in $7 \%$ of the participants $(n=139)$ being removed from the sample.

Of the 1725 participants 59\% were female, and the largest concentration resided in California $8.4 \%$ and Florida $7.8 \%$. At least one representative from all fifty U.S. states was present. The age of the sample ranged from 18-75 (Median $=46, S D=13.64)$ with a median household income range of $\$ 40,000-\$ 49,999$. Eighty-three percent of the sample was Caucasian, $9.3 \%$ African American, and 3.5\% Asian; 8.4\% identified as Hispanic. Sixty-four percent of the sample reported having some college and less than a four-year degree education; while $23 \%$ reported having a 4-year degree and $13.2 \%$ reported having a graduate or professional degree.

\section{RESULTS}

\section{Overall Structural Model}

The hypothesized relationships were assessed using path analyses in AMOS Structural Equation Modeling software. One assumption of structural equation modeling is that all latent 
variables and indicators vary between units. Thus, the analysis assessed the consumers' advertising process with respect to only the first stimuli that participants see. Two path-modeling analyses were conducted. First, we analyzed a model to test the hypothesized general digital ad process detailed earlier. Second, we analyzed a model to test the influence of involvement (i.e., hypotheses 11a, 11b, 12a, and 12b).

Individual measures were first converted into scales by extracting the principle component from each multi-item scale to represent model variables and then paths were drawn to examine the hypothesized relationships.

\section{A General Digital Ad Process Model}

The general model was analyzed using SPSS 22 AMOS statistical modeling software. Figure 3 provides the standardized path coefficients (and significance) of each parameter. The proposed structural model provided a acceptable fit to the study data: $\mathrm{X}^{2}(25)=270.713 p<.001$, normed fit index $(\mathrm{NFI})=.956$, comparative fit index $(\mathrm{CFI})=.960$, root mean square error of application $(\mathrm{RMSEA})=.076$.

Results of the model support hypotheses 1-7 and research questions 1 and 2 of the digital buying process. Each relationship is detailed in Figure 3. In particular:

- Message perceptions were significantly positively related to attitudes towards the advertisement

- Message perceptions were significantly positively related with attitudes towards the brand

- Perceived ad credibility was significantly positively related to attitudes towards the advertisement

- Attitudes towards the advertisement were significantly positively associated with attitudes towards the brand

- Attitudes towards the brand were significantly positively associated with purchase intentions

- Attitudes towards the advertisement were significantly positively associated with intention to search for product information

- Attitudes towards the brand were significantly positively associated with intention to search for information 
- Intention to search for product information was significantly positively associated with purchase intentions

- Intention to search for information was significantly positively associated with the likelihood of clicking-through to receive product information

- Purchase intentions were significantly positively associated with the likelihood of clicking-through to receive product information

Note, regressing gender onto message perceptions controlled for the significant relationship between the two variables. Similarly, the relationships between gender and $A_{A d}$, age and ad credibility, age and intentions, device type and ad credibility, device type and age, device type and search intentions, and device type and click-through were also controlled. 
Figure 3: Structural results of the general advertising process model

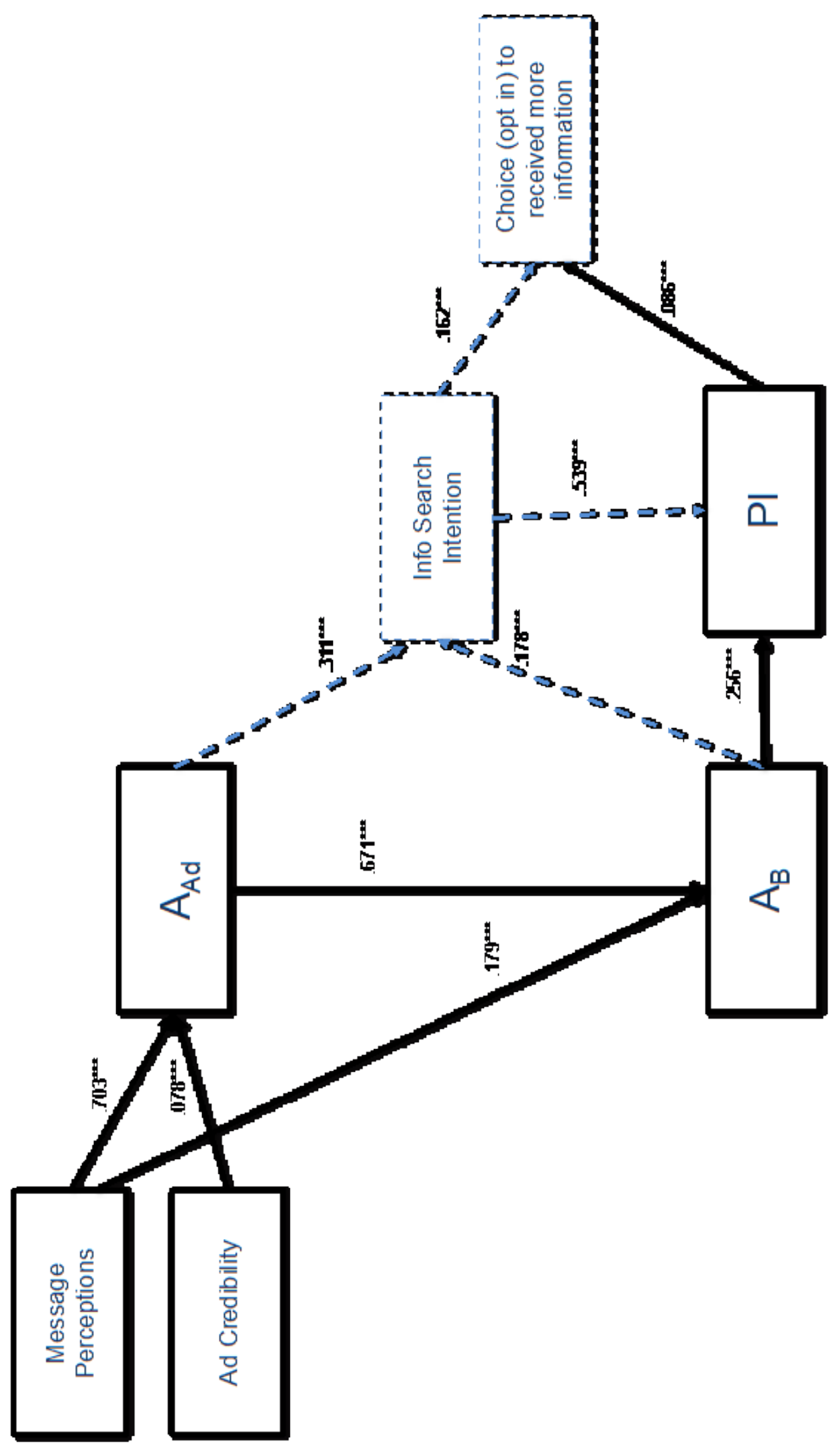




\section{A Dual Digital Ad Process Model}

Next, we conducted a second structural equation model to test hypotheses $8 \mathrm{a}, 8 \mathrm{~b}, 9 \mathrm{a}$ and $9 \mathrm{~b}$, which address how involvement moderates the structure of the digital ad process model. Multigroup path analysis was conducted using invariance testing. The invariance test compares whether the chi-square statistics of the two models - one model for low involvement and one model for high involvement - differs significantly from each. Moreover, this analysis tests which specific parameters differ.

Results of the multi-group model are summarized in Table 2. The proposed structural model provided a good fit to the study data: $\mathrm{X}^{2}(48)=344.174, p<.001$, normed fit index (NFI) $=.935$, comparative fit index $(\mathrm{CFI})=.942$, root mean square error of application $(\mathrm{RMSEA})=.060$. Moreover, when compared to the fully constrained model $X^{2}(64)=523.568, p<.001$, the invariance test supports that involvement moderates the structure of the model (chi-square difference $(16)=179.394, p<.001)$.

Assessing both a $95 \%$ confidence threshold of 348.02 and the difference in slopes by constraining the relevant parameters on at a time, H8a, H8b, H9a and H9b are tested. First, H8a, which states $A_{B}$ will be a stronger predictor of search intentions (SI) when involvement is high (vs. low), was not supported $\left(\mathrm{X}^{2}=344.527\right)$, as the chi-square did not exceed the confidence threshold. However, it is important to note that $\mathrm{A}_{\mathrm{B}}$ is no longer a significant predictor of SI when involvement is high. Thus, the difference in slopes test is not necessary, as a change in the $p$-value suggests that $\mathrm{A}_{\mathrm{B}}$, rather than being be a stronger predictor when involvement is high (vs. low), was not related to SI.

Next, $\mathrm{H} 8 \mathrm{~b}$, which states $\mathrm{A}_{\mathrm{B}}$ will be a stronger predictor of PI when involvement is high (vs. low), was supported $\left(\mathrm{X}^{2}=414.802\right)$. This is also supported by the t-test difference in slopes $(t=$ 
8.27, $p<.001)$. Furthermore, H9a, which states that SI will be a stronger predictor of consumers' likelihood to click-through for more product information (click-through) when involvement is high (vs. low), was supported $\left(\mathrm{X}^{2}=377.686\right)$. This is also supported by the t-test difference in slopes $(t$ $=7.51, p<.001)$.

Lastly, H9b, which states that PI will be a weaker predictor of consumers' click-through for more product information when involvement is high (vs. low), was not supported $\left(\mathrm{X}^{2}=\right.$ 344.175). However, it is important to note that PI is no longer a significant predictor of clickthrough when involvement is high. Thus, the difference in slopes test is not necessary, as a change in the p-value suggests that PI is not related to click-through when involvement is high (vs. low). Taken together, the results are consistent with $\mathrm{H} 12 \mathrm{~b}$.

Table 2: Summary of advertising process models comparing dual processes

\begin{tabular}{|c|c|c|}
\hline \multirow[t]{2}{*}{ Variables } & \multicolumn{2}{|c|}{ Estimate } \\
\hline & Low Involvement & High Involvement \\
\hline Message perceptions $->$ Aad & $.663 * * *$ & $.721 * * *$ \\
\hline Ad credibility $->$ Aad & $.089 * * *$ & .012 \\
\hline Message perceptions $->\mathrm{Ab}$ & $.166 * * *$ & $.208 * * *$ \\
\hline Aad $->\mathrm{Ab}$ & $.661 * * *$ & $.653 * * *$ \\
\hline Aad $->$ Search Intentions & $.222 * * *$ & $.273 * * *$ \\
\hline $\mathrm{Ab}->$ Search Intentions & $.150 * * *$ & .109 \\
\hline $\mathrm{Ab}->\mathrm{PI}$ & $.130 * * *$ & $.439 * * *$ \\
\hline Search Intentions -> PI & $.496 * * *$ & $.223 * * *$ \\
\hline PI -> Choice for additional product info & $.048 * * *$ & .047 \\
\hline $\begin{array}{r}\text { Search Intentions }->\text { Choice for additional } \\
\text { product info }\end{array}$ & $.090 * * *$ & $.252 * * *$ \\
\hline \multicolumn{3}{|l|}{ Control Variables } \\
\hline Gender-> Aad & $.105^{* *}$ & $.121 *$ \\
\hline Age $->$ Search Intentions & $-.010 * * *$ & $-.007 * *$ \\
\hline Age- $>$ PI & $-.006 * *$ & .000 \\
\hline Device Type $->$ Search Intentions & .003 & $-.283 * * *$ \\
\hline Device Type -> Purchase Intentions & -.034 & .082 \\
\hline Device Type -> Choice for additional & -.025 & $-.113 * *$ \\
\hline
\end{tabular}




\begin{tabular}{rcl} 
Variables & \multicolumn{2}{c}{ Estimate } \\
\hline Covariates & \\
\hline product info & $.032^{*}$ \\
\hline Message perceptions $<->$ Gender & $.032^{*}$ & $.358^{* * *}$ \\
\hline Message perceptions $<->$ Ad credibility & $.380^{* * *}$ & $4.626^{* * *}$ \\
\hline Age $<->$ Ad credibility & $-4.594^{* * *}$ & -.003 \\
\hline Device Type $<->$ Ad credibility & .029 & -.514 \\
\hline Device Type $<->$ Age & $-.506^{* *}$ &
\end{tabular}

\section{DISCUSSION AND CONCLUSION}

This study develops a digital advertising framework that accounts for previously studied drivers and consequences of attitudes towards an ad, while adding two digital specific metricsproduct information search intentions and click-through - to the model. We extend the Affect Transfer Hypothesis to examine consumers' processing of digital video advertising, and in doing so enhance our understanding of how digital advertising works. We further offer implication for marketers regarding the relationship between digital advertising and other digital marketing tactics.

\section{Theoretical Implications}

This study contributes to existing literature in digital advertising, information processing and consumer behavior in three ways. First, the extension of the Affect Transfer Hypothesis enhances the current understanding of digital advertising. Scholars have suggested that further advancement in digital marketing requires linking empirical research with established theories (Bart, Stephen and Sarvary 2014; Grassmann and Brettel 2015). Moreover, few digital advertising models account for recent shifts in consumers' digital purchase behavior. However, this study has generated an empirical test for how digital advertising works and accounted for consumers' heavy reliance on product information search on digital platforms. We demonstrate an empirical relationship between brand attitudes and product information search intentions (SI), as well as a 
relationship between SI and purchase intention. Consequently, this research offers a coherent framework that identifies drivers and consequences of attitudes towards digital ads.

In doing this we demonstrate that the Affect Transfer Hypothesis is a useful theoretical framework for better understanding consumers response to online or mobile advertising, as we had consumers take the study on laptops, tablets and smartphones. Indeed, by including search intentions in the model we expand its ability to explain digital advertising effectiveness. Additionally, by simulating click through likelihood we further understand the role of purchase intentions in digital advertising. Specifically, consumers purchase intentions are related to click through likelihood.

Second, our digital advertising model allows for the simultaneous examination of the long understood relationship between attitude towards advertisement, brand attitudes and purchase intentions along with a novel digital based relationship between brand attitudes, search intentions (SI) and purchase intentions. Specifically, consumers' perceptions about digital video ads indirectly predict their intentions to search for more information about the product. Thus, researchers might consider whether digital video ads push consumers to search, thereby enhancing search engine marketing effectiveness. Prior studies have systematically examined consumers' intentions to search for information, an integral antecedent of purchase intentions from online a buying process, though this is the first study to do so for digital advertising (Choi and Rifon 2002; Shim, Eastlick, Lotz and Warrington 2001). Consumer's search intentions are increasingly important to marketers because search marketing expenditures are increasing and omin-channeling allows consumers to search online as well as in-store (Nielsen 2016; Wang, Malthouse and Krishnamurth 2015). 
Third, by taking the perspective of the consumer to examine digital advertising effectiveness, our study complements previous research that has primarily focused on individual customers and traditional response variables (Bart, Stephen and Sarvary 2014). Both academic and industry sources tout the importance of search metrics in digital marketing (Srinivasan, Rutz and Pauwels 2015; Alldredge, Newaskar and Ungerman 2015). Interestingly, the results of this study support that intentions to search are a fundamental variable in the digital advertising process, as search intentions are positively related purchase intentions, and both search intentions and purchase intentions and positively related to consumers' likelihood of opting for more product information.

Fourth, by distinguishing the roles of purchase and search intentions in the process, we extend prior theory on the attitude-behavior link, as purchase intentions were not as salient in a digital-based high involvement advertising process as search intentions. With regard to the nature of consumer involvement, we find that when consumers are in the market for a product, they are more likely to click-through for more product information when they have search intentions. On the other hand, although being in the market to buy a product is often seen as the rationale for active customer involvement, it does not increase the relationship between purchase intention and opting in for more information. The intention-behavior link (Fishbein and Ajzen 1975), influenced by digital video advertising, appears to be contingent on the specific action. In particular, certain intentions may not be relevant in predicting certain actions, such as click-through (vs. purchase). Engagement is a key metric in digital advertising; however, involvement or the personal relevance of a product to the consumers must not be overlooked. Consumers have access to endless information anywhere, and because of omnicommerce, they are almost able to purchase anytime. 
The days of watching a TV ad, and having a lag till purchase are behind us. Consequently, involvement is an integral piece to understanding digital advertising. Consumers can go from liking to purchase in minutes. For consumers who are identified as "not in the market" for the product, marketers can focus on affecting search intentions, as they lead to purchase intentions and click-through more product information. However, for consumers who are identified as "in the market" for the product, marketers can focus on affecting brand attitudes, which predict to purchase intentions. More over the click-through should not lead to more information, but directly to commerce.

\section{Managerial implications}

Prior research has shown that consumers use the Internet as a source of information and inspiration (Sands et al. 2016). In particularly, digital consumers are searching for ideas, rather than simply optimizing the price of a purchase. Consequently, consumers' product information search is assumed to be a central step in the pre-purchase process. Accounting for search in a digital advertising process allows for a better understanding of digital advertising and how it might impact other marketing communication tactics. With abundant information available to consumers from ostensibly unlimited and often unfamiliar sources, marketers must understand how their advertising influences consumers search of such information.

From a managerial perspective, we address emerging issues around increased spending on mobile media. Findings from this research implicate search intentions as a key metric for digital marketing. Further, the research suggests that managers should promote search intentions as well as purchase intentions on a laptop, while mobile strategies may not benefit as much. As the proliferation of mobile platforms continues, video-search engine marketing may become a key strategy for companies. We demonstrate that search intentions are important predictors of purchase 
intentions, while purchase intentions lead to a consumer clicking-through to be sent more information. Inspiring the consumer to engage the company, using a 15-second video advertisement, relies on many factors including the ad credibility, the message perceptions, and the consumer's attitudes towards the ad and brand.

\section{Limitations and future research}

This research examined the changes in consumers' advertising process in a digital context. However, a comparison to traditional platforms (e.g., TV) was not made. Though the results of this research are robust, future studies might examine the same advertising process with respect TV. Doing so would possibly enhance the authors' conclusion that the advertising process is evolving along with technology.

Additionally, mobile platforms are implicitly different than more traditional laptops in their mobility, display of information, and sensory experience afforded. On a mobile platform, purchase may not be the consumer's immediate goal. If consumers are moving around, purchase intentions may not be as salient in the consumer's advertising process (eMarketer 2014b). Consequently, mobile platforms may inspire consumers to respond to advertising differently than they do on laptops. Future research should examine whether consumers prefer laptops for product research by testing whether platform type moderates the advertising process. When consumers are not in the market to buy a product, will the platform (laptop vs. smartphone) affect the ads influence on their pursuit of more product information? The finding of this research greatly enhance our understanding of digital advertising, as well uncover questions that can be examined to directly impact marketing theory and practice. 


\section{References}

AJZEN, I. \& FISHBEIN, M. 1980. Understanding attitudes and predicting social behaviour.

AJZEN, I. \& FISHBEIN, M. 1977. Attitude-behavior relations: A theoretical analysis and review of empirical research. Psychological bulletin, 84, 888 .

ALBAUM, G., ROSTER, C. A. \& SMITH, S. M. 2015. Topic sensitivity: Implications for webbased surveys. The Sustainable Global Marketplace. Springer.

ALLDREDGE, K., NEWASKAR, P., \& UNGERMAN, K. 2015. The digital future of consumerpackaged-goods companies. McKinsey \& Company. Available from:

http://www.mckinsey.com/industries/consumer-packaged-goods/our-insights/the-digitalfuture-of-consumer-packaged-goods-companies [Accessed $14^{\text {th }}$ July 2017].

ANDERSON, M. 2015. Technology Device Ownership: 2015. Pew Research Center. Available from http://www.pewinternet.org/2015/10/29/technology-device-ownership-2015 [Accessed $14^{\text {th }}$ July 2017].

ANDREWS, J. C. \& SHIMP, T. A. 1990. Effects of involvement, argument strength, and source characteristics on central and peripheral processing of advertising. Psychology \& Marketing, 7, 195-214.

BART, Y., STEPHEN, A. T. \& SARVARY, M. 2014. Which products are best suited to mobile advertising? A field study of mobile display advertising effects on consumer attitudes and intentions. Journal of Marketing Research, 51, 270-285.

BATRA, R. \& RAY, M. L. 1986. Affective responses mediating acceptance of advertising. Journal of consumer research, 13, 234-249.

BELTRAMINI, R. F. 1988. Perceived believability of warning label information presented in cigarette advertising. Journal of Advertising, 17, 26-32.

BISWAS, A., PULLIG, C., YAGCI, M. I. \& DEAN, D. H. 2002. Consumer evaluation of low price guarantees: The moderating role of reference price and store image. Journal of Consumer Psychology, 12, 107-118.

BROWN, S. P., HOMER, P. M. \& INMAN, J. J. 1998. A meta-analysis of relationships between ad-evoked feelings and advertising responses. Journal of Marketing Research, 114-126.

BROWN, S. P. \& STAYMAN, D. M. 1992. Antecedents and consequences of attitude toward the ad: A meta-analysis. Journal of consumer research, 19, 34-51.

BURKE, M. C. \& EDELL, J. A. 1989. The impact of feelings on ad-based affect and cognition. Journal of marketing research, 69-83.

CHAIKEN, S. \& MAHESWARAN, D. 1994. Heuristic processing can bias systematic processing: Effects of source credibility, argument ambiguity, and task importance on attitude judgment. Journal of personality and social psychology, 66, 460-460.

CHANG, A., HSIEH, S. H. \& TSENG, T. H. 2013. Online brand community response to negative brand events: the role of group eWOM. Internet Research, 23, 486-506.

CHOI, S. M. \& RIFON, N. J. 2002. Antecedents and consequences of web advertising credibility: A study of consumer response to banner ads. Journal of Interactive Advertising, 3, 12-24.

DUTTA-BERGMAN, M. 2003. Trusted online sources of health information: differences in demographics, health beliefs, and health-information orientation. Journal of medical Internet research, 5.

EDELL, J. A. \& BURKE, M. C. 1987. The power of feelings in understanding advertising effects. Journal of consumer research, 14, 421-433. 
eMarketer. 2015a. Mobile to Account for More than Half of Digital Ad Spending in 2015: Will surpass desktop for the first time this year. eMarketer. Available from:

http://www.emarketer.com/Article/Mobile-Account-More-than-Half-of-Digital-AdSpending-2015/1012930. [Accessed 14 ${ }^{\text {th }}$ July 2017].

eMarketer. 2015b. Mobile Apps vs. Mobile Browsers: How usage, Ad spending, and mobile commerce sales differ by channel. eMarketer. Available from: http://www.emarketer.com/articles/results.aspx?q=mobile apps\&ecid=MX1087. [Accessed $14^{\text {th }}$ July 2017].

eMarketer. 2015c. Mobile Commerce Roundup. eMarketer. Available from: https://www.emarketer.com/public_media/docs/eMarketer_Mobile_Commerce_Roundup .pdf. [Accessed 14 ${ }^{\text {th }}$ July 2017].

eMarketer. 2014a. 2 Billion Consumers Worldwide to Get Smart(phones) by 2016: Over half of mobile phone users globally will have smartphones in 2018. eMarketer. Available from: http://www.emarketer.com/Article/2-Billion-Consumers-Worldwide-Smartphones-by2016/1011694 [Accessed 14 ${ }^{\text {th }}$ July 2017].

eMarketer. 2014b. Mobile Search Will Surpass Desktop in 2015: Mobile to pass desktop in search ad dollars next year. eMarketer. Available from: http://www.emarketer.com/Article/Mobile-Search-Will-Surpass-Desktop-2015/1011657 [Accessed 14 ${ }^{\text {th }}$ July 2017].

eMarketer. 2013a. Consumers Choose Digital for Product Research, Purchases. eMarketer. Available from: http://www.emarketer.com/Article/Consumers-Choose-Digital-ProductResearch-Purchases/1010948 [Accessed 14 ${ }^{\text {th }}$ July 2017].

GARDNER, M. P. 1985. Mood states and consumer behavior: A critical review. Journal of Consumer research, 12, 281-300.

GLASMAN, L. R. \& ALBARRACÍN, D. 2006. Forming attitudes that predict future behavior: a meta-analysis of the attitude-behavior relation. Psychological bulletin, 132, 778.

GOLDSMITH, R. E., LAFFERTY, B. A. \& NEWELL, S. J. 2000. The impact of corporate credibility and celebrity credibility on consumer reaction to advertisements and brands. Journal of advertising, 29, 43-54.

HARMON, R. R. \& CONEY, K. A. 1982. The persuasive effects of source credibility in buy and lease situations. Journal of Marketing research, 255-260.

HÄUBL, G. \& TRIFTS, V. 2000. Consumer decision making in online shopping environments: The effects of interactive decision aids. Marketing science, 19, 4-21.

LAROCHE, M., KIM, C. \& ZHOU, L. 1996. Brand familiarity and confidence as determinants of purchase intention: An empirical test in a multiple brand context. Journal of business Research, 37, 115-120.

LUTZ, R. J. 1985. Affective and cognitive antecedents of attitude toward the ad: A conceptual framework. Psychological processes and advertising effects, 45-64.

MACKENZIE, S. B. \& LUTZ, R. J. 1989. An empirical examination of the structural antecedents of attitude toward the ad in an advertising pretesting context. The Journal of Marketing, 48-65.

MACKENZIE, S. B., LUTZ, R. J. \& BELCH, G. E. 1986. The role of attitude toward the ad as a mediator of advertising effectiveness: A test of competing explanations. Journal of marketing research, 130-143.

MAITY, D. \& ARNOLD, T. J. 2013. Search: an expense or an experience? Exploring the influence of search on product return intentions. Psychology \& Marketing, 30, 576-587. 
MATTHES, J. 2013. The affective underpinnings of hostile media perceptions: Exploring the distinct effects of affective and cognitive involvement. Communication Research, 40, 360-387.

MERCHANT, A. \& ROSE, G. M. 2013. Effects of advertising-evoked vicarious nostalgia on brand heritage. Journal of Business Research, 66, 2619-2625.

MITCHELL, A. A. \& OLSON, J. C. 2000. Are product attribute beliefs the only mediator of advertising effects on brand attitude? Advertising \& Society Review, 1.

MUK, A. \& CHUNG, C. 2015. Applying the technology acceptance model in a two-country study of SMS advertising. Journal of Business Research, 68, 1-6.

Nielsen. 2016. What Are Connected Shoppers Doing and Not Doing Online?. Nielsen.com. Available from: http://www.nielsen.com/us/en/insights/news/2016/what-are-connectedshoppers-doing-and-not-doing-online.html. [Accessed 14 ${ }^{\text {th }}$ July 2017].

OHANIAN, R. 1991. The impact of celebrity spokespersons' perceived image on consumers' intention to purchase. Journal of advertising Research.

OLSON, M. A. \& FAZIO, R. H. 2008. Implicit and explicit measures of attitudes: The perspective of the MODE model.

PETTY, R., PRIESTER, J. \& BRIÑOL, P. 2002. Mass media attitude change: implications of the elaboration likelihood model of persuasion." i Jennings, B. \& D. Zillman (red). Media effects: advances in theory and research.

PETTY, R. E. \& CACIOPPO, J. T. 1986. The elaboration likelihood model of persuasion. Advances in experimental social psychology, 19, 123-205.

PETTY, R. E., CACIOPPO, J. T. \& GOLDMAN, R. 1981. Personal involvement as a determinant of argument-based persuasion. Journal of personality and social psychology, $41,847$.

PETTY, R. E., CACIOPPO, J. T. \& SCHUMANN, D. 1983. Central and peripheral routes to advertising effectiveness: The moderating role of involvement. Journal of consumer research, 10, 135-146.

PETTY, R. E., HAUGTVEDT, C. P. \& SMITH, S. M. 1995. Elaboration as a determinant of attitude strength: Creating attitudes that are persistent, resistant, and predictive of behavior. Attitude strength: Antecedents and consequences, 4.

PETTY, R. E. \& WEGENER, D. T. 1998. Matching versus mismatching attitude functions: Implications for scrutiny of persuasive messages. Personality and Social Psychology Bulletin, 24, 227-240.

PORNPITAKPAN, C. 2004. The persuasiveness of source credibility: A critical review of five decades' evidence. Journal of applied social psychology, 34, 243-281.

PUNJ, G. 2012. Consumer decision making on the web: A theoretical analysis and research guidelines. Psychology \& Marketing, 29, 791-803.

REINHARD, M.-A. \& SPORER, S. L. 2010. Content versus source cue information as a basis for credibility judgments. Social Psychology.

ROY DHOLAKIA, R. \& STERNTHAL, B. 1977. Highly credible sources: Persuasive facilitators or persuasive liabilities? Journal of Consumer Research, 3, 223-232.

SANDS, S., FERRARO, C., CAMPBELL, C. \& PALLANT, J. 2016. Segmenting multichannel consumers across search, purchase and after-sales. Journal of Retailing and Consumer Services, 33, 62-71.

SHERMAN, S. J. \& FAZIO, R. H. 1983. Parallals between attitudes and traits as predictors of behavior. Journal of personality, 51, 308-345. 
SHIM, S., EASTLICK, M. A., LOTZ, S. L. \& WARRINGTON, P. 2001. An online prepurchase intentions model: The role of intention to search. Journal of retailing, 77, 397-416.

SHIMP, T. A. 1981. Attitude toward the ad as a mediator of consumer brand choice. Journal of advertising, 10, 9-48.

SLATER, M. D. \& ROUNER, D. 1996. How message evaluation and source attributes may influence credibility assessment and belief change. Journalism \& Mass Communication Quarterly, 73, 974-991.

SPEARS, N. \& SINGH, S. N. 2004. Measuring attitude toward the brand and purchase intentions. Journal of Current Issues \& Research in Advertising, 26, 53-66.

SRINIVASAN, S., RUTZ, O. J. \& PAUWELS, K. 2016. Paths to and off purchase: quantifying the impact of traditional marketing and online consumer activity. Journal of the Academy of Marketing Science, 44, 440-453.

Statista. 2015. Number of worldwide internet users from 200 to 2015: Global Internet Usage Report. Statista. Available from: http://www.statista.com/statistics/273018/number-ofinternet-users-worldwide/.[Accessed $14^{\text {th }}$ July 2017].

STEWART, K. \& CUNNINGHAM, I. 2017. Examining Consumers' Multiplatform Usage And Its Contribution to Their Trust in Advertising. Journal of Advertising Research, JAR2017-003.

STIFF, J. B. 1986. Cognitive processing of persuasive message cues: A meta-analytic review of the effects of supporting information on attitudes. Communications Monographs, 53, 75 89.

STIFF, J. B. \& BOSTER, F. J. 1987. Cognitive processing: Additional thoughts and a reply to Petty, Kasmer, Haugtvedt, and Cacioppo.

VATANPARAST, R. \& ASIL, M. 2007. Factors affecting the use of mobile advertising. International Journal of Mobile Marketing, 2.

WANG, R. J.-H., MALTHOUSE, E. C. \& KRISHNAMURTHI, L. 2015. On the go: How mobile shopping affects customer purchase behavior. Journal of Retailing, 91, 217-234.

WORTHINGTON, A. K., NUSSBAUM, J. F. \& PARROTT, R. L. 2015. Organizational credibility: The role of issue involvement, value-relevant involvement, elaboration, author credibility, message quality, and message effectiveness in persuasive messages from public health advocacy organizations. Communication Research Reports, 32, 199207.

YANG, Z. J. 2012. Too scared or too capable? Why do college students stay away from the H1N1 vaccine? Risk Analysis, 32, 1703-1716.

YAZDANPARAST, A. \& SPEARS, N. 2013. Can consumers forgo the need to touch products? An investigation of nonhaptic situational factors in an online context. Psychology \& Marketing, 30, 46-61. 
Appendix A: Platform verification survey questions

What device are you currently responding to this survey with?

- Laptop/Notebook Computer Device

- Tablet Device

○ Smartphone Device

○ Other

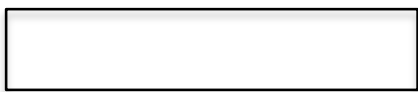

○ Don't know/Not sure

Just to clarify. Have a look at the device you are currently using. Please select the picture below that looks most like the device you are on right now.

○

○

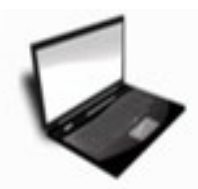

$\circ$
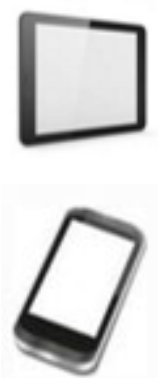
Appendix B: Example of Stimuli

Melt Chocolate

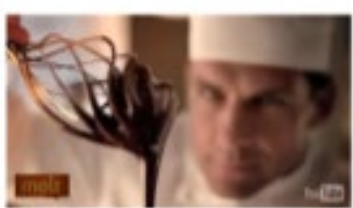

\section{melt}

Royal Oceana Cruise
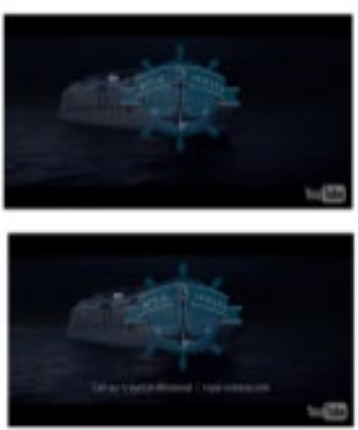

Pearl Toothpaste
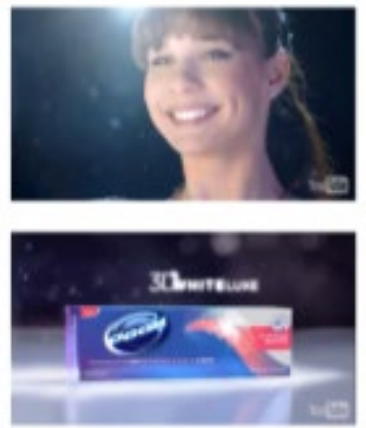

Lenor Detergent
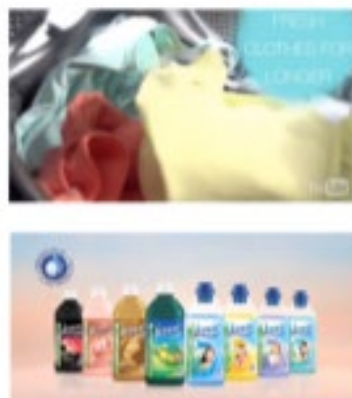

Vive Minivan

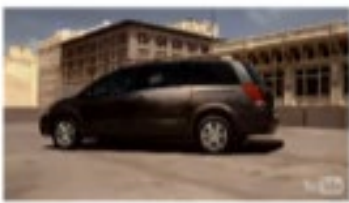

NEW VIVE GRAND CA PICASSO

Wax 'n Wick Scented Candles
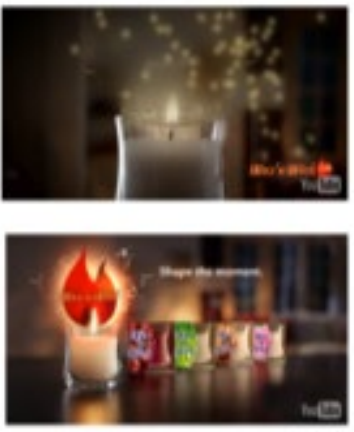

Zepto Laptop
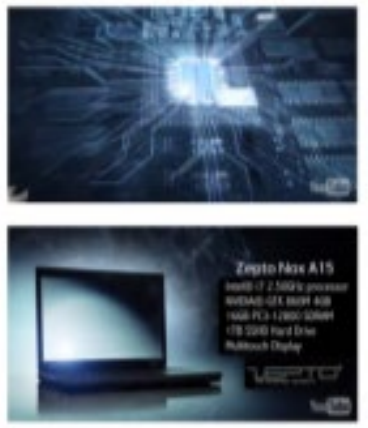

Forte Music Festival
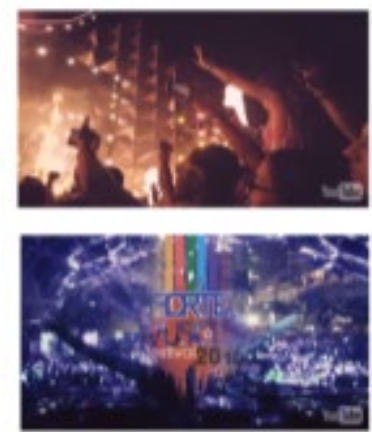
Appendix C: Manipulation check of stimuli

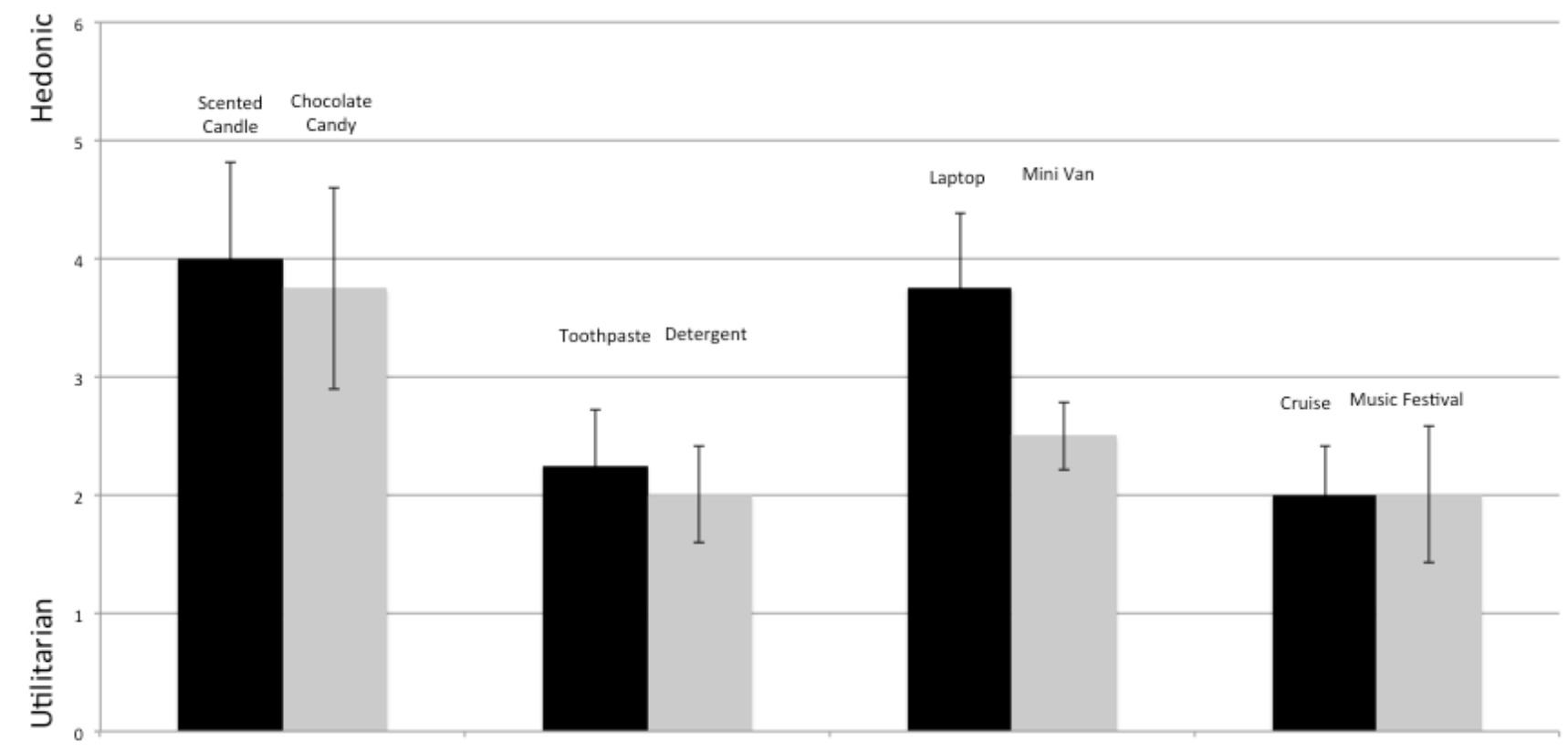

